CENTRE FOR ECONOMIC PERFORMANCE

OCCASIONAL PAPER NO. 5

MAY 1994

LESSONS FROM ECONOMIC TRANSFORMATION

AND THE ROAD FORWARD

S. GOMULKA 


\section{INTRODUCTION}

This paper contains the text of a guest lecture delivered by Dr Gomulka to the Nordic Finance Committee at its meeting in Lillehammer, Norway, on 21 January 1994 at the invitation of Kjell Storvik, Deputy Governor of the Central Bank of Norway and the Chair of the meeting. The Committee is composed of top representatives of Central Banks and Finance Ministries of the five Nordic countries: Denmark, Finland, Iceland, Norway and Sweden.

This paper was produced as part of the Centre's

Programme on Post-Communist Reform 


\section{LESSONS FROM ECONOMIC TRANSFORMATION \\ AND THE ROAD FORWARD}

Stanislaw Gomulka

Page

1. Reform strategy 1

2. The output collapse has been inevitable 3

3. Money has been the key nominal anchor 4

4. The exchange rate policy 5

5. The public finance crisis and the fiscal policy

6. Mr Klaus' Ten Commandments 6

7. A closer look at Russia 9

8. The special case of Poland 11

$\begin{array}{ll}\text { Endnote } & 13\end{array}$

$\begin{array}{ll}\text { References } & 14\end{array}$

I wish to acknowledge helpful comments by Audun Gronn of the Norges Bank and by Peter Boone and Mark Schaffer of the London School of Economics. The Centre for Economic Performance is financed by the Economic and Social Research Council. 


\title{
LESSONS FROM ECONOMIC TRANSFORMATION AND THE ROAD FORWARD
}

\author{
Stanislaw Gomulka*
}

My primary purpose is to comment on the experiences so far by the formerly communist countries in transforming their economies with a view to proposing lessons for policy-making. Although my familiarity is greatest with the Polish experience I shall make use of the empirical evidence, both economic and political, from the whole area of Central and Eastern Europe and the Former Soviet Union (FSU), particularly Russia.

I begin with a few general observations about the choice of reform strategy. This I follow with a discussion of the output collapse and the conduct of macroeconomic policies. The Ten Commandments of $\mathrm{Mr}$ Klaus provide me with a further opportunity to comment on policies. Finally, I shall take a closer look at Russia and comment briefly on developments in Poland.

\section{Reform Strategy}

The change of economic system now under way in Central and Eastern Europe and the FSU requires, of course, major structural shifts in terms of institutions, ownership, modes of interpersonal behaviour, attitudes to work and laws. Some institutions have to be cut in size or closed down, others expanded or created. These institutional changes are superimposed on large changes in the pattern of prices and foreign trade relations, both of which imply major shifts in the required composition of output. In particular, exports to the former Council for Mutual Economic Assistance (CMEA) area and the shares of industry in GDP have to fall and did fall dramatically. On the other hand, the share of trade and financial services should increase and are increasing sharply.

In terms of institutions, skills, prices and products, there is therefore a large distance between the initial point where a post-communist economy finds itself just before the reforms and the end point of its intended transition. Reform strategy is about the speed and sequence of reforms to effect the transition. 
A policy designer, in proposing a broad reform strategy and specific policies, has also to take into account particular economic circumstances as well as political constraints. These circumstances relate above all to the sizes of internal and external disequilibria and the possible extent of external assistance.

The strategy has therefore five major components: microliberalisation, macro-stabilisation, structural changes, safety nets and external assistance. Of these the first three are crucial components of any reform package. External assistance is typically small and of limited impact even though it may be useful for political reasons to exaggerate its significance by both donors and recipients.

The inherited circumstances fall into two categories, common and country-specific. The common part dominates and ensures that the reform policies and transition paths exhibit some basic similarities among countries. Nevertheless, the variation in country-specific circumstances is substantial enough to have a major impact on the choice of overall reform strategy as well as specific policies.

The similarities are possibly greatest with respect to rapid microliberalisation and some important structural changes, notably rapid reorientation of foreign trade and privatisation. Somewhat unexpectedly, the greatest differences have emerged in the area of macroeconomic policy.

Three broad reform strategies may be distinguished: the so called shock therapy, managed shock and gradual. The true shock therapy was applied only in East Germany where Western prices were imposed from one day to the next. Although subsidies remained in place, the instant monetary union meant that local producers were offered no protection against West German products. Moreover, real wages for political reasons were increased sharply. The outcome is well known: drastic collapse of industrial output, massive unemployment and external assistance of some $\$ 100$ billion per year. Although this strategy offers the potential for a fast reallocation of resources, it is far too costly in the short and medium term to be of interest to any other post-communist country. At the other end of the spectrum is the truly gradual strategy. This has been pursued successfully only by China since the late 1970s. The strategy had been tried also in Central Europe, especially in Hungary and Poland, but with insufficient vigour and poor results. In conditions of severe economic and 
political crisis, virtually the only choice open for the FSU and Central Europe was therefore a form of managed shock. A strong form of it was adopted by Poland, Latvia, Estonia and Czecho-Slovakia and a more gradual variant in most other transition economies, particularly Russia.

\section{The Output Collapse Has Been Inevitable}

Unusually large output declines during the initial phase of transition are probably the socially gravest and the most politically dangerous economic phenomenon. The critics of radical reforms have tended to associate these declines with, in their view, excessively restrictive macroeconomic policies. However, it is now clear and this is possibly the key lesson from the cumulative experience of transition countries during the last four years, that the output declines have little to do with the conduct of macroeconomic policy. It would appear that, given the large weight and commonality of inherited economic problems (and the fast speed with which the transition has taken place), the recessions inevitably have to be deep and fairly long everywhere.

The range of measured GDP falls is nevertheless quite wide, from about $17 \%$ in Poland to about $50 \%$ in parts of Central Europe and the FSU. The recession appears to be deeper whenever; the initial price distortions are larger, the price liberalisation is faster, the private sector is smaller, the defence sector is larger and the intra-CMEA trade accounts for a larger proportion of GDP. Price liberalization contributes to recession by virtue of the fact that it leads to prices increasing much faster than wages and other income. This results in large falls of real purchasing power. The falls, however, are necessary in order to eliminate the forced buying of goods (forced substitution) so that the market mechanism can begin to function. Price liberalization results also in changed relative prices which require large changes in the entire product composition of the supply side. Owing to the presence of various rigidities, substantial resources become permanently useless or idle until redeployed and/or improved to produce the goods which, under new prices and new trade links, are in demand and profitable.

The immediate implication of this interpretation of output falls is that post-reform sustainable supplies should form J-curve patterns. The further implication is that macroeconomic policies of the authorities must 
not attempt to regain the earlier levels of real aggregate demand. That demand must be allowed to fall to the level of much reduced aggregate supply. In other words, the essentially structural causes of these recessions imply that they cannot be reversed in a Keynesian way through an expansion of nominal aggregate demand. By far the dominant, if not the only, effects of any such expansion are higher prices and/or higher net imports.

The experience also shows that the needed supply-side adjustments take place much faster in the private sector than in the state sector. Consequently, the size of the private sector at the start of the transition appears to be the single most important factor influencing the size of initial output fall and the speed of subsequent recovery.

\section{Money Has Been the Key Nominal Anchor}

In most countries of Central and Eastern Europe it was assumed that stabilization of the liberalised prices must be based on the standard International Monetary Fund (IMF) approach with an important role for nominal anchors assigned to a tough incomes policy and a fixed exchange rate, in addition to a restrictive monetary policy. However, the money supply has emerged to be by far the dominant nominal anchor with the exchange rate and the incomes policy playing no role or only supportive roles. With respect to the exchange rate there were good reasons, such as low levels of international reserves and poor credibility of macroeconomic policies, why large up-front devaluations were necessary. But the immediate consequence of such devaluations was that large gaps opened up between domestic and world prices for tradables, so that, initially, world prices offered little discipline on domestic prices. The other potential anchor, an incomes policy, was intended to help to achieve a given inflation rate with a less restrictive monetary policy and hence a possibly smaller recession. However, given the large risks and uncertainties, it has proved difficult to coordinate the anchor role of the two policies, incomes and monetary. In Poland in 1990 and Czecho-Slovakia in 1991, for instance, monetary policies were initially so restrictive that incomes policies were not binding in most enterprises. In the FSU the authorities took the view that a really restrictive incomes policy could not be implemented for political reasons. Moreover, in Russia the politically dependent Central 
Bank became excessively concerned with the level of economic activity, typically the domain of governments. A wage-price inflationary spiral was the consequence.

In the pursuit of a proper monetary policy, the experience has been that credit limits can be used successfully by the Central Bank, especially in the initial few years of the transition. Consequently, the real interest rates need not be positive to begin with but they should not be strongly negative as they have been in most of the FSU. However, the rates may have to be strongly positive in the intermediate stage of transition when credit limits are lifted and the real exchange rate has had time to appreciate. In that stage the interest rate becomes the key policy instrument to protect international reserves, induce savings and restrain wage inflation.

\section{The Exchange Rate Policy}

A large upfront devaluation at a unified rate has proved to be an effective policy during the vital initial phase to protect domestic producers and to replenish international reserves. Consequently, internal convertibility was achieved in many countries and has been successfully maintained. However, it is important not to overburden the exchange rate with its role as a nominal anchor in the later stages of transition. The Polish experience suggests that the policy of a pre-announced crawling peg is a very good follow-up, provided the switch to it from the fixed rate regime is not unduly delayed.

\section{The Public Finance Crisis and the Fiscal Policy}

In all transition countries, with the notable exception of Hungary, budget deficits are financed almost wholly by bank credit. Moreover, the velocity of money circulation tends to be high, especially in those countries which are experiencing or have recently experienced a hyperinflation. The combination of the two features is that budget deficits are highly inflationary. An independent role for Central Banks and their monetary policies is fairly limited. Yet all transition countries, with the notable exception so far of the Czech Republic, appear to suffer from a crisis of public finance. Therefore the political will and administrative ability to control a budget deficit effectively determines the success or failure of a stabilisation programme. Some countries, notably Hungary and Poland, 
have already accumulated a large public debt. In these countries the rapidly rising cost of servicing the debt and above all the high and rising social transfers are the two categories of public expenditures which together are emerging as posing the greatest threat to macroeconomic stability.

\section{Mr Klaus' Ten Commandments}

In his address to the Group of Thirty at its Spring 1993 Plenary meeting in Vienna, Mr Klaus, the present Prime Minister of the Czech Republic, summarised his experiences as a major reformer in the form of Ten Commandments for what he calls profound, fundamental, structural reforms. Let me remind you of these Commandments and comment on them. They are as follows:

(i) Reforms in post-communist countries are the outcome of a complex social and political process and therefore cannot be pre-planned or socially-engineered by any one person or centre.

(ii) The role of foreign aid is marginal.

(iii) An economic shock, meaning a large fall of output, is inevitable.

(iv) Dramatic actions are required to impose a restrictive macroeconomic policy, liberalise prices and foreign trade, and establish a process for privatisation.

(v) Restrictive macroeconomic policy must be sustained.

(vi) The price shock resulting from price liberalisation must be vigorously defended and survived.

(vii) Economic restructuring requires comprehensive privatisation.

(viii) Transformation costs must be widely shared. 

goods and the free flow of people and ideas.

Successful transformation requires successful politicians.

I take these propositions in the spirit in which, I believe, they were proposed, as important messages but not as universal laws of nature. With this proviso, I have no particular problems in endorsing them. My comments are therefore intended only to offer some modifications to some of these propositions.

The reforms are not just the outcome of a political process as the First Commandment asserts. After all, the purpose of transition is not to invent something new but imitate the well-known solutions of marketbased capitalist economies of the West European type. Reformers do have specific reform blueprints which they then attempt to implement through the political process. These are useful to have even if the timetable, the sequencing and the methods of their implementation may change. Given the huge cost of standing still or going back, the ultimate result is still unlikely to be much different from the original blueprint.

With respect to foreign aid, I have already suggested its marginal size and role for most countries. The reason is self-evident. Using purchasing power parities, per capita GDP in the FSU and Central Europe was just before the reforms, some $\$ 5000$. Therefore, the total GDP of all the transition countries was about 2000 billion US dollars. The investment needed to restructure economies of that size sufficiently, so that at the least the pre-reform level of GDP is regained, is probably of the same order of magnitude; that is, some $\$ 2000$ billion. The resources of the IMF and the World Bank are clearly too small by comparison and can in any case be provided only on a commercial basis and therefore subject to conditions which economies in transition cannot easily meet. Having said that, there are a few small countries in which foreign aid, especially in the form of grants and debt reductions, can be said to have been vital.

I have already argued in favour of Commandments Three to Seven which form the core of any determined reform effort. Short-term costs arising from conducting a restrictive macroeconomic policy appear small, while medium and long-term gains are clearly large. The experience of 
some countries, notably Russia, suggests that a successful stabilization policy is not a necessary precondition for the implementation of the other truly transformation-related reforms, particularly privatization and liberalization of prices and foreign trade. However, once policy and attention moves from transformation to recovery and sustainable growth, macroeconomic stabilization becomes essential.

A similar caveat can be made with respect to $\mathrm{Mr}$ Klaus's Commandment Seven, concerning the need for rapid privatisation. In Poland the state-driven privatisation has been slow. Yet, a rapid autonomous growth of the private sector, which is the organic privatisation favoured by Professor Kornai, has ensured that the sector accounted, in 1993, for about $60 \%$ of total employment and about $50 \%$ of GDP. So again, rapid privatisation of the existing state sector is helpful but may not be as necessary as Mr Klaus thinks.

The Tenth Commandment is also an exaggeration. Successful politicians are helpful but not necessary for a successful transformation. Reform, of course, must be legitimized through a democratic political process. This is vital. But the socially costly phase of transition comes at a time when democratic institutions are in their infancy. Consequently there are typically too many small parties with ill-defined policies, the division of power between the main central institutions is often unclear and many politicians lack experience of efficient communication with the electorate. Such circumstances often produce confusion and political instability which of course hinder the process of economic reform and pose a continual threat to democratic politics. The result of this so far has been frequent changes of government and in many cases, legislative nearparalysis. In this respect the Czech Republic is an exception to the rule. However, the experience has also been that frequent changes of government provide an opportunity to employ the political capital of a large pool of politicians which is in the interest of the transformation during the socially costly phases of reform.

\section{A Closer Look At Russia}

There has been much confusion about what kind of strategy Russia has followed and much discussion about policies which the country should follow - less shock and more therapy or more shock and more therapy. The 
questions to be answered are these; What view should we have about the strategy underlining Russian reforms so far? Was it a shock therapy at all? Was it excessively gradual? With respect to macroeconomics policies, why have they been so inflationary? Were they completely irrational? What are we to expect now, following the results of recent parliamentary elections and the departure of Yegor Gaidar from the Russian cabinet?

Concerning the last two years, our evaluation of reforms should be clear - Russia in its own chaotic manner has followed a managed shock therapy. After all, the three main components of that strategy have been implemented; (1) fast liberalisation of most prices, including the exchange rate, permitting the replacement of central planning by market coordination; (2) considerable foreign trade liberalisation, leading to large shifts in the geographical and product composition of trade; and (3) a large progress in privatisation and other structural changes. Russia's reforms have been extremely gradual only with respect to inflation. But low inflation is neither necessary nor sufficient to effect systemic transformation. There remains also the historical fact that low inflation was observed in Russia under Stalin and Brezhnev and hyperinflations were experienced by many market economies. The three components I mentioned above, and they alone, are the core of the transformation.

However, Russia's macroeconomic policies have clearly been excessively inflationary. The reasons are not completely transparent. We know that Russia's inflation crisis has been almost purely a monetary phenomenon (Easterly and da Cunha, 1993), driven by large budget deficits and subsidised credits to economic units. My experience is that when output is falling fast all over the place, as a result of fast systemic transformation, there is a sense of terror in the corridors of power. The danger of a chain reaction looms large, whereby some bankruptcies will lead abruptly to a sequence of other bankruptcies and ultimately to a nearly total disintegration of the economy. Hence the apparent need is felt to retain subsidies, at least in the most politically or socially sensitive sectors, such as defence and agriculture. However, in Russia these subsidies have been vastly excessive, at some $15 \%$ of GDP - about the same as before the start of transition. It is also interesting that Russia's assistance to the other republics of the FSU has been very high, probably much greater than the combined Western assistance to these countries. The new Russian state has 
thus been intent on maintaining its old strategic priorities: imperial influence, selected industrial capacities and a strong military. The priorities are pursued with perhaps less vigour now than in the communist past but still at a considerable expense in terms of the progress of reform and the living standards of Russian people. What is clear and alarming, is that the policy is not just that of the Russian Central Bank or some ministers, but also, indeed above all, of the country's President and Parliament.

Russia has arrived at the start of 1994 , at a crossroad similar to that which Poland reached two years ago following Poland's first free parliamentary elections and the departure of Leszek Balcerowicz. At that time the Olszewski government was strongly critical of earlier policies and initially intended to reflate the economy. However, key economic ministers (and myself as their macroeconomics adviser) managed to persuade the government, even without the help of the IMF, that the scope for safe anti-recessionary policies was extremely limited and more or less sensible policies were adopted.

The chance of Russia adopting a different course leading to even more inflation, widespread price controls and more subsidies is now, unfortunately, uncomfortably high. The inflation tax paid by households was, in 1992, estimated as 12\% of GDP (Easterly and da Cunha, 1993). The dollarization of savings and an increase of real interest rates are leading to a decline of the base for the inflationary tax and consequently an increase in the velocity of money circulation. Without the political strong will to confront the situation there is now a clear danger of a sharp increase of inflation and a renewed large capital flight.

On the positive side, Russia is already close to the end of the first phase of transition; one of liberalisation, demolition and construction. The cumulative fall of measured GDP during 1991-93 has been close to $40 \%$. In the course of 1994 the country should enter the consolidation phase, in which the level of activity is stable and unemployment low but rising. The balance of trade has already improved vastly and the rapid privatisation process, if continued, should lead soon to the appearance of first islands of recovery and growth. A new decree, dated 27 October 1993, legalising the purchase and sale of land, should speed up the privatisation of agriculture. The electoral success of Mr Zhirinovsky and his far-right nationalist party 
is potentially an extreme danger in the medium term, especially in terms of foreign policy but may induce cooperation among reformers and alarm the nation's political centre.

\section{The Special Case of Poland}

Poland is the country with the lowest transition-related fall in industrial output and GDP in Central and Eastern Europe. It has also been the first transition country to experience, in the years 1992-93, a significant economic recovery. On the demand side, the recovery has been very much consumption-led. Following a sharp fall, by about $15 \%$ in 1990, private consumption has increased in the three years $1991-93$ by about $20 \%$. On the supply side, the driving force has been the private sector. This sector apparently suffered no recession even in the first year of transition and has been expanding very fast during the last three years. However, even Poland will have great difficulties in sustaining growth at a rate commensurate with a low and constant rate of unemployment. The two major Polish problems are likely to be typical for most transition economies: low savings and high public expenditures, requiring high taxation and considerable public dis-saving. The concern to protect living standards has so far dominated the attention of both households and the authorities. Consequently, the rate of inflation and the rate of interest are still high and the rate of investment is low. There is therefore the danger that the rate of unemployment - at about $16 \%$, very high already - will continue to increase.

Despite these problems, Poland looks, and is at the start of 1994, an island of success in an ocean of misery and distress. While the worst also seems to be over for a few other transition countries, notably the Czech Republic and possibly Hungary, most are likely to remain in a state of acute crisis for some time yet. 


\section{ENDNOTE}

The author has been Economic Adviser to Poland's successive Finance Ministers since September 1989 supported financially by the British Government's Know-How Fund. As a member of the Balcerowicz Group he advised the Polish Government on the elaboration and implementation of the 1990-91 reform. In 1990-91 he was a member of the Polish delegation negotiating the debt reduction with the Paris and London Clubs. In the period 1989-93 he participated in all negotiations with the IMF and the World Bank concerning macroeconomic and other policies for Poland. He also advised the Russian Government, in the second half of 1991, on the liberalization and stabilization policies for 1992. At the London School of Economics he is Reader in Economics in the Department of Economics and Director of the CEP's Programme on Post-Communist Reform. 


\section{REFERENCES}

Åslund, A., "Conclusions from the First Four Years of Systemic Changes in Eastern Europe", CASE, Warsaw, December 1993, mimeo.

Easterly, W. and da Cunha, P. V., "Financing the Storm: Russia's Inflation Crisis", The World Bank, Washington DC, mimeo, 1993.

Fan, Q. and Schaffer, M., "Government Financial Transfers and Enterprise Adjustments in Russia, with Comparison to Central and Eastern Europe", London School of Economics, Centre for Economic Performance Working Paper No. 394, 1993.

Gomulka, S., "The Causes of Recession Following Stabilization", Comparative Economic Studies, 32(2), 1991, pp.71-89.

Gomulka, S., "Polish Economic Reform, 1990-91: Principles, Policies and Outcomes", Cambridge Journal of Economics, 16, 1992, pp.355-372.

Gomulka, S., "On the Design of Economic Policy: The Challenge of E a ste $\mathrm{r} n$

$\mathrm{Eu}$ r o $\mathrm{p} e$ , i $n$ $\mathrm{H}$.

Sie ber $\mathrm{t}$ (ed .), Ec on 
$\underline{\mathbf{O}}$

$\underline{\mathrm{mi}}$

$\underline{\mathrm{c}}$

G r

OW

$\mathrm{th}$

in

W

orl

d

E c

$\underline{\mathrm{On}}$

$\underline{\mathrm{O}}$

my

I C

B

M

o h

r

( P

aul

Sie

b e

ck)

$\mathrm{T} \mathrm{u}$

bin

g e

n ,

19

93 
Gomulka, S., "Economic and Political Constraints During Transition", Europe-Asia Studies (formerly Soviet Studies), Vol. 46, No. 1, 1994.

Illarionov, A., Layard, R., and Orszag, P., "The Conditions of Life", ch. 9 i $n$

A .

$\AA \mathrm{s}$

$1 \mathrm{u}$

$\mathrm{nd}$

( E

d.)

$E c$

$o n$

om

$i c$

$T r$

a $n$

sfo

$r m$

ati

$o n$

in

$R u$

ssi

$a$,

Lo

$\mathrm{nd}$

on:

$\mathrm{P} \mathrm{i}$

nte

r

$\mathrm{Pu}$

bli 
Klaus, V., "The Ten Commandments of Systemic Reform", Group of Thirty, Occasional Paper No. 43, Washington DC, 1993.

Kornai, J., "Transformation Recession", Economic Appliquee, 1993.

Rostowski, J., "The Interenterprise Debt Explosion in the Former Soviet Union: Causes, Consequences, Cures', London School of Economics, Centre for Economic Performance, Discussion Paper No. 142, April 1993.

Schaffer, M., "Polish Economic Transformation: From Recession to Recovery and the Challenges Ahead", Business Strategy Review, Vol. 4, No. 3, Autumn 1993, pp.53-69. 